\title{
Abstract Reasoning and Friendship in High Functioning Preadolescents with Autism Spectrum Disorders
}

\author{
Marjorie Solomon • Nirit Buaminger • \\ Sally J. Rogers
}

Published online: 14 May 2010

(C) The Author(s) 2010. This article is published with open access at Springerlink.com

\begin{abstract}
To investigate the relationship between cognitive and social functioning, 20 Israeli individuals with HFASD aged 8-12 and 22 age, maternal education, and receptive vocabulary-matched preadolescents with typical development (TYP) came to the lab with a close friend. Measures of abstract reasoning, friendship quality, and dyadic interaction during a play session were obtained. As hypothesized, individuals with HFASD were significantly impaired in abstract reasoning, and there were significant group differences in friend and observer reports of friendship quality. There also was consistency in reports between friends. Two factors- "relationship appearance" and "relationship quality" described positive aspects of the relationships. Disability status and age related to relationship appearance. Proband abstract reasoning was related to relationship quality.
\end{abstract}

M. Solomon · S. J. Rogers

Department of Psychiatry and Behavioral Science, University of California, Davis, Sacramento, CA, USA

M. Solomon · S. J. Rogers

M.I.N.D. Institute, University of California, Davis, Sacramento,

CA, USA

M. Solomon

Imaging Research Center, 4701 X Street, Sacramento, CA

95817, USA

N. Buaminger

School of Education, Bar Ilan University, 52900 Ramat Gan, Israel

M. Solomon $(\varangle)$

Department of Psychiatry and Behavioral Science, MIND Institute, 2825 50th Street, Sacramento, CA 95817, USA

e-mail: marjorie.solomon@ucdmc.ucdavis.edu
Keywords Autism spectrum disorder . Asperger Syndrome · Friendship · Abstract reasoning · Intimacy $\cdot$ Responsiveness

\begin{abstract}
Abbreviations
HFASD High functioning autism spectrum disorders or persons with these disorders

TYP Individuals with typical development
\end{abstract}

\section{Introduction}

High functioning autism spectrum disorders (HFASDs) including high functioning autism, Asperger's Disorder, and pervasive developmental disorder NOS (PDDNOS) are characterized by impairments in social functioning and language, and by the presence of restricted interests and repetitive behaviors. Impairments in executive functions are among the most consistently reported deficits in individuals with autism spectrum disorders (Hill 2004; Ozonoff et al. 2006; Verté et al. 2006). It has been difficult to document clear relationships between measures of impairments in executive functions and measures of autism-related behaviors (e.g. Geurts et al. 2009).

\section{Abstract Reasoning and HFASD}

Abstract reasoning, which is an element of executive functioning, requires the considerations and manipulation of information about events, objects, and concepts not in the immediate environment. Abstract reasoning is thought to involve both the ability to identify concepts (i.e. to recognize underlying category attributes so as to better 
understand them), and the ability to form concepts (i.e. to generate cognitive schemas to organize information) based on these discriminations.

Concept identification abilities, emerge during the first year of life in typical development, and children with autism appear to acquire simple classification abilities involving the physical world (e.g. the ability to sort objects) similarly to children with other developmental delays (Ungerer and Sigman 1987; Tager-Flusberg 1985). However, it is unclear whether individuals with autism can categorize based on more representational and abstract criteria. Some have found that lower functioning children have difficulty with sorting tasks that involve abstract categories (Shulman et al. 1995; Ropar and Peebles 2007), though older higher functioning individuals do not appear to have these difficulties (Minshew et al. 2002).

In contrast to concept identification, concept formation involves an "open field" situation in which the individual must initiate the cognitive processes required to solve a problem. The ability to generate schemas to organize social and non-social behavior is an example of concept formation. This type of initiation, or "generativity," is recognized as a deficit area for children (Bishop and Norbury 2005), and adults (Ambery et al. 2006; Minshew et al. 2002; Turner 1999) with HFASD. Concept formation, but not concept identification, as assessed by the Goldstein-Scheerer object sorting task, has been found to differentiate children with HFASD from others, correctly identifying $89 \%$ of cases of autism in individuals aged 12 and above (mean age $=21$ ) with HFASD in a discriminant function analysis (Minshew et al. 2002).

\section{Preadolescent and Adolescent Development} and Friendship

Social impairments, which are among the most handicapping symptoms of autism (Rogers 2000), have been conceptualized as involving deficits in affective reciprocity (Hobson 1996), in theory of mind (Saxe and Baron-Cohen 2006), and in imitating/mirroring the actions of others and thereby intuiting their intention (Hobson and Lee 1999; Rizzolatti and Fabbri-Destro 2008; Rogers 2007). While these areas have been relatively well-studied, there has been little research about cognitive and developmental aspects of friendship quality in individuals with HFASD. This represents a significant gap in the literature because the ability to achieve sustained friendship is one of the most clinically important and ecologically-valid indicators of social functioning (Bauminger and Kasari 2000).

Friendship is critical for human development. It provides a context for social, moral, and emotional growth (Bukowski et al. 1996; Bukowski and Sippola 1996; Howard et al. 2006; Rubin et al. 1998). In addition to its importance in promoting development, the quality of preadolescent and adolescent friendship is related to multiple important outcomes including self-esteem (Berndt 1996), depression and school adjustment (Hartup 1995), and loneliness and social dissatisfaction (Parker and Asher 1993). Friendship, and the social support it provides, also serves as a protective factor against the development of psychopathology (Berndt 1989; Rubin et al. 1998; Sullivan 1953), while problematic peer relationships are associated with depressed mood and loneliness (Boivin et al. 1994; Parker et al. 1999).

Despite folk wisdom to the contrary, research suggests that friendship is highly desired by individuals with HFASD (Henault and Attwood 2002; Howard et al. 2006; Jones and Meldal 2001; Stokes and Kaur 2005), although the level of social functioning of children, preadolescents, and adolescents on the autism spectrum is variable (Orsmond et al. 2004). While deep and intimate friendship is beyond the grasp of many such individuals, for others, positive, sustained, and even sexual relationships (see Stokes et al. 2007) are possible (Bauminger 2004; Orsmond et al. 2004). The friendships of individuals with HFASD may differ from those found in typically developing ones with respect to duration, frequency of meetings, activities undertaken (Bauminger and Shulman 2003), and composition of the disability status of the dyad (Bauminger and Shulman 2003; Bauminger et al. 2008a).

The achievement of intimacy, which involves the ability to integrate a partner's needs and perspectives with one's own, is considered the most critical milestone for typical adolescent friendship (Grotevant and Cooper 1986; Selman 1990), and intimacy of friendship in adolescence is related to adjustment and to interpersonal competence (Buhrmester 1990). The ability to attain intimacy is likely made possible by the maturation of executive functions including selective attention, behavioral control, perspective taking, organization, decision making, planning, and abstract reasoning that occur in typical preadolescent and adolescent brain development (Luna et al. 2004; Spear 2000; Yurgelun-Todd 2007). Indeed, behavioral researchers have linked the maturity of adolescent friendship to cognitive development during this period (Hartup 1996).

\section{Linking Abstract Reasoning and Friendship Abilities}

Deficits in concept formation may limit the ability of individuals with HFASD to generate cognitive schemas that promote the efficient organization of social and non-social information. Impairments in the ability to create organizing schemas for initiating new social behaviors and routines (i.e. meeting new people, entering different and unstructured social situations, and/or conducting reciprocal conversations) would greatly disrupt daily social functioning. Similarly, the inability to conceptualize, represent, and integrate multiple perspectives would produce deficits in interpersonal 
relationships. The replicated finding that concept formation abilities and the demonstration of cognitive generativity is predictive of play quality in younger children supports the assertion that concept formation abilities are related to real world social functioning (see Jarrold et al. 1996; Rutherford and Rogers 2003; Rutherford et al. 2007).

\section{Goals of the Current Study}

The overarching goal of the current study was to examine relationships between abstract reasoning abilities in HFASD and social functioning involved in friendship. We used an ecologically valid approach involving multi-informant and multi-method assessment consisting of trained observer (Q-sort based ratings across two semi-structured tasks) and friend reports (a self-report inventory) of friendship quality. We had three main hypotheses. Consistent with literature from older samples, we hypothesized that individuals with HFASD would have impairments in concept formation, but not in concept identification. We tested this on age, gender, and receptive vocabulary matched groups of children with and without HFASD using the DKEFS Sorting Task. Second, as shown in our previous work, we hypothesized that the relationships of participants with HFASD would be less intimate, and that friend perceptions in the dyad would be more variable, than those seen in children without ASD. To test this hypothesis, we examined relationship quality within and between dyads consisting of HFASD and TYP probands. Given their trajectory in typical development, we also hypothesized that relationship intimacy would increase with age, and we tested this exploratory hypothesis by examining correlations between observer and friend reports of relationship quality and age. Third, we hypothesized there would be links between abstract reasoning abilities in individuals with HFASDs and their social functioning as measured by the ability to form strong and reciprocal friendships. We tested this hypothesis by examining the relationship between abstract reasoning variables in individuals with HFASD, and friendship quality measures.

\section{Data Analysis}

Analyses were completed in SPSS version 16.0. Hypothesis one was test using a one-way analysis of covariance (ANCOVA) where PPVT score was used as a covariate, given that the groups differed on this variable. For hypothesis two, between group differences on friendship variables were examined by means of Mann-Whitney U tests for independent samples. Within group differences (i.e. those involved in proband/friend pairs) were examined by means of Wilcoxon Signed Rank tests. Exploratory correlational analyses that examined the relationship between age and friendship intimacy were conducted using Spearman's rho correlations (2-tailed). To examine the fourth hypothesis about the relationship between cognitive factors (abstract reasoning) and social functioning (friendship quality), we first conducted a principal components factor analysis with varimax rotation to reduce the number of friendship quality variables. These were followed up using multiple regression analyses that examined the relationship between disability status, age, abstract reasoning abilities, and relationship quality.

\section{Method}

\section{Participants}

Participants in the current study included 42 target children from the Israeli sample of a large multi-national study of friendship and attachment in high functioning children with autism spectrum disorders. The larger project, which is more fully described in Bauminger et al. (2008b), included a group of HFASD and a control group of typically developing children. Diagnostic criteria for the HFASD children in Israel included prior clinical diagnosis based on the DSM$I V$; American Psychiatric Association (1994) and a verification of clinical diagnosis by the Autism Diagnostic Interview-Revised (ADI-R; Lord et al. 1994). The present study focused on 20 preadolescents with HFASD (mean age $=9.78 ;$ standard deviation $[\mathrm{SD}]=4.7$ with one girl) and 22 preadolescents (mean age $=10.29 ; \mathrm{SD}=16.9$ with one girl) with typical development from the Israeli sample for whom abstract reasoning measures had been collected.

This part of the Israeli sample included 8 (40\%) children with $\mathrm{HF}$ autism and $12(60 \%)$ children with Asperger syndrome. The primary difference between HF autism and Asperger Syndrome is the presence of significant language delay before the age of 3 years in the former. The decision to include children with autism and those with AS was based on the shared social characteristics for both populations, during middle childhood (see, for example, Paul 2003).

Additional inclusion criteria were: (a) CA between 8 and 12 years; (b) a receptive language score of 80 or above as assessed by the Peabody Picture Vocabulary Test Third Edition, which is explained below (PPVT-III; Dunn and Dunn 1997); (c) normative reading comprehension level based on the reading subtest of the Ma'akav (Shany et al. 2003); and (d) an identified close friend of at least 6 months (duration of the friendship was determined through open-ended questioning prior to the proband's inclusion in the study). See Table 1.

\section{Friends of HFASD and TYP}

Each target HFASD child participated in the study with one identified close friend. Some of the target children's friends 
Table 1 Participant Characteristics $(n=42)$

\begin{tabular}{lccllc}
\hline & \multicolumn{2}{l}{ Autism $(n=20)$} & & \multicolumn{2}{l}{ Control $(n=22)$} \\
\cline { 2 - 3 } \cline { 6 - 6 } & $M(\mathrm{SD})$ & Range & & $M(\mathrm{SD})$ & Range \\
\hline Males & 19 & & 21 & \\
Age (Months) & $116.5(14.06)$ & $98-151$ & & $122.95(17.1)$ & $98-144$ \\
PPVT* & $105.0(10.32)$ & $84-122$ & & $112.36(6.97)$ & $101-128$ \\
Mother's & $4.63(.955)$ & $3-6$ & & $4.55(1.36)$ & $2-6$ \\
ADIR-Soc & $16.9(3.48)$ & $10-25$ & & NA & \\
ADIR-Comm & $13.25(4.41)$ & $8-22$ & & NA & \\
ADIR-RB & $5.25(1.41)$ & $3-8$ & & NA & \\
\hline
\end{tabular}

* PPVT scores differed significantly between the groups

also had a disability. In this sample, 9 friends (45\%) had a disability ( 8 with an autism spectrum disorder, and one with another disorder), while 11 friends (55\%) were typically developing. The majority of children had friends within 1 year of their age, although, on average, probands were 5 months older than their friends. Eighty percent of the friends of children with HFASD were boys. The remaining $20 \%$ were girls. The typically developing sample brought $86 \%$ male friends and $14 \%$ female friends. While more children with HFASD brought friends to the lab who were of the opposite gender, there was no significant difference in this percentage.

\section{TYP Group}

Best efforts were used to match the HFASD to TYP groups on maternal education (which was obtained during the initial interview and was rated on a numerical scale based on whether a mother had some high school or had graduated [3], had some college [4] or had graduated [5], or had a post graduate level education [6]), receptive vocabulary from the Peabody Picture Vocabulary Test-(PPVT; Dunn and Dunn 1997), CA, and gender (see Table 1). In this sample, there was a significant difference between the PPVT scores of the groups. The mean age difference between typically developing children and their friends was 1 month.

\section{Measures}

Abstract Reasoning- D-KEFS Sorting Test from The Delis Kaplan Executive Function System (Delis et al. 2001)

The Delis Kaplan Executive Function System (D-KEFS) is used to assess executive functions, specifically those related to perseveration, cognitive flexibility, ideational and design fluency, and inhibition in individuals from age $8-89$. Most of its nine subtests are adaptations of traditional research measures refined to examine a wider range of skills with more precision and fewer confounds. The Sorting Test, which is the focus of this study, is an assessment instrument designed for isolating and measuring multiple components of concept identification and concept formation. There are two test conditions: sort recognition and free sorting. Test materials consist of two sets of 6 cards each that can be sorted into two groups of three cards in a variety of ways based on perceptual (color, size, shape, background patter, lettering study) and conceptual (descriptive words written on the cards) features. The dependent variables used in this manuscript are: sorts identified, sorts generated, and sort descriptions. This is considered a test of conceptualization and reasoning skills, and cognitive flexibility. The D-KEFS Sorting Test has exhibited acceptable levels of internal consistency, testretest reliability, and validity.

\section{Friendship Observation-Two Friendship Experimental Scenarios: Construction Game and Drawing}

Target children (HFASD and Typical) were invited to come to the laboratory with a close friend. Each dyad was observed and videotaped during a 40-min session while participating in two different noncompetitive tasks: the "construction game" scenario and the "drawing" scenario. The construction game scenario followed Siperstein, Leffert, and Wenz-Gross's (1997). In this scenario, children were provided with a noncompetitive construction game-Discovery Toys' Super Marbleworks ${ }^{\circledR}$ Raceway Construction Set. Children were instructed to construct a shared design (a marble maze). After completion, children could roll the marbles down the maze. In the drawing scenario, children were given a box of colored markers and a large blank sheet of paper. Children were asked to draw a shared design. Order of administration of the construction game and shared drawing scenarios was counterbalanced.

\section{Observer and Friend Reports of the Functioning of the Dyad}

As described below, two methods of assessing the social functioning of the dyad were used: (a) an observer rated Q-sort based measure (Dyadic Relationship Q-Set or DRQ) and (b) a self-report behavioral inventory measure of the quality of the friendship provided by the target child and his friend (Friendship Qualities Scale or FQS).

\section{Dyadic Relationships Q-Set}

The 55-item Dyadic Relationships Q-Set (DRQ) (Park and Waters 1989) was used to evaluate dyadic behavioral 
dimensions. These 55 items were sorted in a fixed distribution into 7 piles, with a 5-7-9-13-9-7-5 distribution. The 7 piles, in forced-choice format, ranged from Least characteristic behavior (pile 1) to Most characteristic behavior (pile 7) for each dyad. A score for an item equaled the pile in which it was placed (e.g., an item in pile 3 received a score of 3). The 55 items were grouped into the following seven dyadic relationship dimensions, which described the quality of interactions among friends: positive social orientation (e.g., "partners express enjoyment at playing together"); cohesiveness (e.g., "when one partner moves away, the other moves in coordination"); harmony (e.g. "offers and suggestions guide dyadic play"); responsiveness (e.g., "partners endorse each other's attitudes and activity preferences"); coordinated play (e.g., "partners work together to produce more complex or organized play than either would engage in alone,"); control (e.g., "partners grab and take things from each other"); and self-disclosure (e.g., "partners share secrets"). The self-disclosure dimension in the current study rarely emerged; therefore, we removed it from our analyses. Two new blind coders coded all tapes and reached a correlation $(r)$ ranging between .70 and .90 , along the different tapes. For each item, the value used for data processing was the mean of the two observers' scores for a description of the DRQ + FQS items see Fig. 1.

Fig. 1 A description of the scales of both the friendship quality scale and the dyadic relationships Q-set
Dyadic Relationships Q-Set (DRQ)

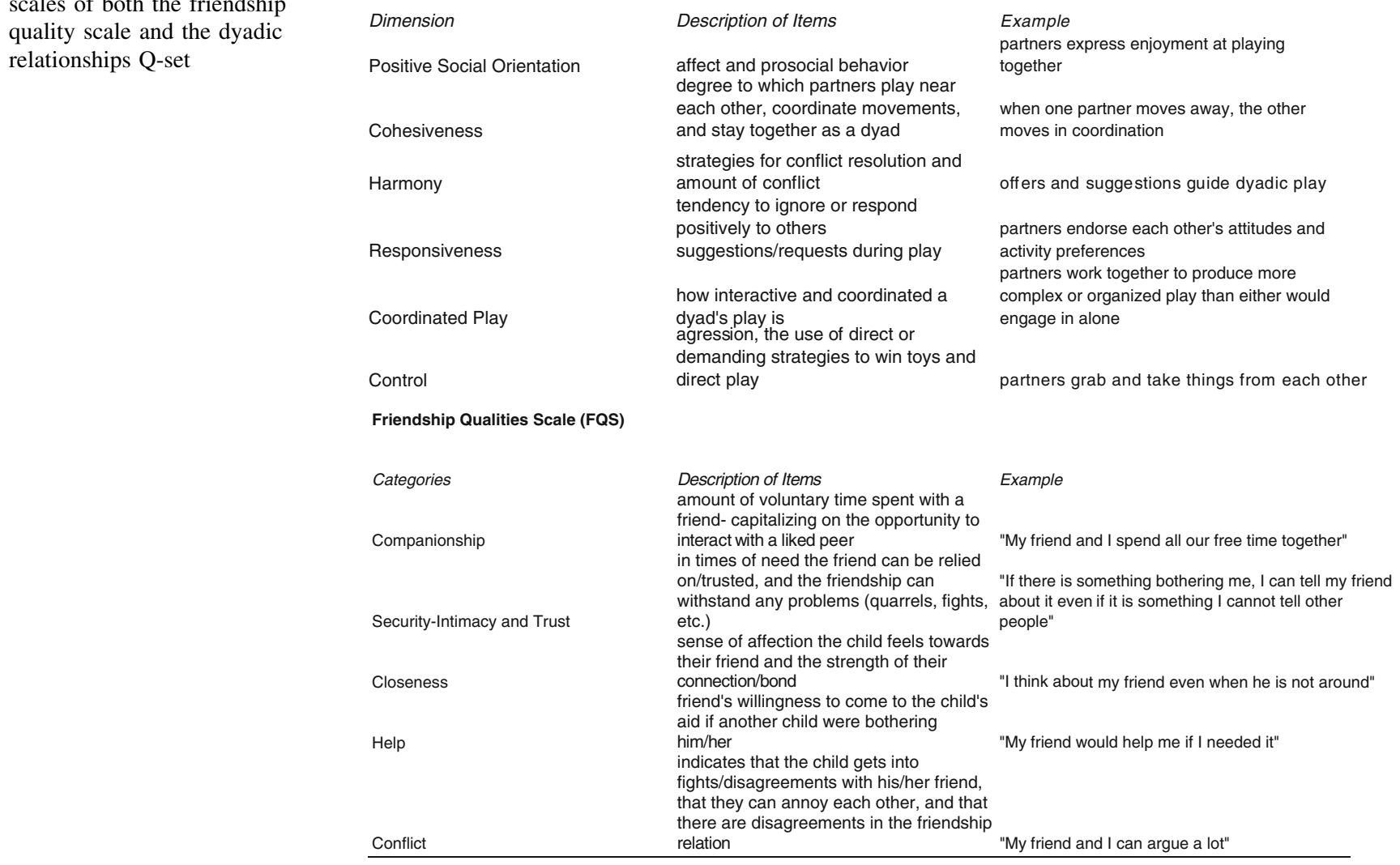

Friendship Qualities Scale (Bukowski et al. 1994)

The Friendship Qualities Scale (FQS) is a self-report assessing children's perception of various qualities of their friendship. Target children and their friends were asked to think about their friendship with each other when answering the questionnaire. The FQS self-report contained 23 items, rated on a 5-point scale ranging from Not true at all (1) to Very true (5). The items reflected five categories of friendship qualities: companionship (e.g., "My friend and I spend all our free time together"); security-intimacy and trust (e.g., "If there is something bothering me, I can tell my friend about it even if it is something I cannot tell other people"); closeness (e.g., "I think about my friend even when he is not around"); help (e.g., "My friend would help me if I needed it"); and conflict (e.g., "My friend and I can argue a lot"). The five subscales presented adequate internal reliability (Cronbach (coefficients between .71 and .86 for Bukowski et al. 1994; and between .57 and .86 in the current study). In this study, we focused on the friend's report of his experience of friendship with the target child.

\section{Reading Tests}

Children completed the Ma'akav (Shany et al. 2003), a standardized measure of decoding and comprehension with 
national norms and acceptable psychometric properties. All children who participated in the study demonstrated sufficient reading abilities to carry out the self-report instruments, based on the age norms of their reading skills and the age levels of the normative groups for the tasks.

\section{Peabody Picture Vocabulary Test Third Edition (Dunn and Dunn 1997)}

We administered the Peabody Picture Vocabulary Test Third Edition (PPVT-III) to all target children in their native language in order to have a brief assessment of children's receptive language ability, to provide both a vocabulary match and to assure that both groups would understand the experimenter instructions. The PPVT is a well standardized, widely used assessment with strong psychometric properties. Scores correlate very highly with multiple other measures of general language ability and cognitive ability (Sattler 1988).

\section{Data Analysis}

The relationship between the abstract reasoning scores and demographic variables including proband age, receptive vocabulary score, and ADI-R domain scores was examined first. For variables that were ordinal and/or not normally distributed, Spearman's rank correlations (two-tailed) were used. Next, between group comparisons of performance on the three abstract reasoning variables were completed using analysis of covariance (ANCOVA) with PPVT score as a covariate reflecting the different receptive vocabulary scores of the groups. Next, the two measures of dyadic relationship quality-observer based Q-sorts and friend's reports of friendship quality, were examined both across groups and within dyads using non-parametric tests next a principal components analysis with varimax rotation was conducted to reduce the number of friendship quality variables to three main factors. Finally, multiple regression analyses were conducted, with age, PPVT, disability status, ADI-R communication score, and abstract reasoning score regressed on the 3 factors underlying relationship quality.
Table 2 Relationship of abstract reasoning and age, PPVT, and ADI-R domain scores for the HFASD group

\begin{tabular}{lccc}
\hline & $\begin{array}{l}\text { Sort } \\
\text { identification }\end{array}$ & $\begin{array}{l}\text { Sort } \\
\text { generation }\end{array}$ & $\begin{array}{l}\text { Sort } \\
\text { description }\end{array}$ \\
\hline Age & .03 & .12 & .12 \\
PPVT score & .08 & -.02 & .02 \\
ADI-R & & & \\
Socialization & -.27 & -.21 & -.17 \\
Communication & $-.57^{* *}$ & $-.51^{*}$ & -.42 \\
Behavior & -.20 & .20 & .12 \\
\hline
\end{tabular}

Correlations are Spearman's Rho (2-tailed)

* Correlation Significant at the $p<.05$ level (2-tailed)

** Correlation significant at the $p<.01$ level (2-tailed)

\section{Results}

Concept Identification and Concept Formation

For the HFASD group only, the relationships between abstract reasoning and demographic variables including age, receptive vocabulary as assessed by PPVT standard score, and severity of autism symptoms based on ADI-R social, communication, and repetitive behavior domain scores were examined using Spearman's rank correlations. There were statistically significant negative correlations between scores on the ADI-R communication scale and sort identification $(r=-.570, p=.009)$ and sort generation $(r=-.510, p=.022)$. There were no other statistically significant correlations between abstract reasoning and demographic variables for the HFASD group. See Table 2.

We next investigated group differences on the D-KEFS variables related to number of sorts recognized, number of sorts generated, and quality of sort descriptions using ANCOVA with the PPVT score used as a covariate to reflect the different receptive vocabulary scores of the groups. The HFASD group performed significantly worse than the typically developing group for sorts identified $(F(2,41)=5.95$, $\left.p=.019, \eta_{\mathrm{p}}^{2}=.13\right) ;$ sorts generated, $(F(2,41)=6.18$, $\left.p=.017, \eta_{\mathrm{p}}^{2}=.14\right)$; and quality of sort descriptions $(F(2$, $\left.41)=8.24, p=.007, \eta_{\mathrm{p}}^{2}=.17\right)$. See Table 3 .

Table 3 Group differences in abstract reasoning variables

\begin{tabular}{|c|c|c|c|c|c|c|}
\hline & \multicolumn{2}{|c|}{ HFASD group $(n=20)$} & \multicolumn{2}{|c|}{ Typically developing group $(n=22)$} & \multirow[t]{2}{*}{$F$} & \multirow[t]{2}{*}{ Significance level } \\
\hline & Mean (SD) & Range & Mean (SD) & Level & & \\
\hline Sort identification & $8.40(3.45)$ & $3.00-9.00$ & $11.36(2.44)$ & $11.00-13.00$ & 5.95 & .019 \\
\hline Sort generation & $8.30(3.29)$ & $4.00-9.00$ & $11.18(3.02)$ & $8.00-14.00$ & 6.18 & .017 \\
\hline Sort description & $8.55(3.07)$ & $4.00-9.00$ & $11.55(2.36)$ & $9.00-14.00$ & 8.24 & .007 \\
\hline
\end{tabular}

PPVT score is used as a covariate in all analyses 
Friendship Quality

Mann-Whitney U tests for independent samples were used to examine group differences in both observer-based Q-sort measures of interaction quality and friend report measures of friendship quality. The groups exhibited significantly different scores on all Q-sort scales-positive social orientation $(z=3.27, p=.001)$, cohesiveness $(z=2.29$, $p=.022)$, harmony $(z=3.24, p=.001)$, coordinated play $(z=3.84, p=.001)$, responsiveness $(z=3.73$, $p=.001)$, and conflict $(z=3.29, p=.001)$, with the HFASD group exhibiting lower scores (Table 4).

As shown in Table 5, there were fewer group differences in both proband and friend reports of friendship quality on the FQS domains, which included companionship, security-intimacy and trust, closeness, help, and conflict. HFASD and typically developing probands differed on subscales scales measuring help $(z=3.48$, $p=.001)$, intimacy $(z=3.43, p=.001)$, and closeness $(z=2.42, p=.016)$, with the HFASD group again scoring lower. The friends of individuals with HFASD and the friends of TYP only differed significantly in their friendship ratings of help $(z=2.56, p=.011)$ and intimacy $(z=2.73, p=.006)$. To assess dyadic consistency in ratings of friendship for both the HFASD and the TYP groups, we compared members of each dyad's scores on the five domains of the FQS using Wilcoxon signed-ranks tests for paired samples. In the group with HFASD probands, there were no significant differences between reports of either member of the dyad on any of the subscales. This also was true for most scales in the dyads consisting only of typically developing individuals, although they differed significantly on their reports of the intimacy of the relationship $(z=2.528, p=.011)$. Here the target participants reported a higher level of intimacy in the relationship than did their friends.

Finally we examined developmental effects on friendship in both groups by investigating relationships between chronological age and: (1) the observer Q-sort variables coded based on the dyad's interactions in the construction and drawing scenarios, and (2) friend reports on the FQS using Spearman's rank correlations. See Table 6. For the typically developing group, there were several significant relationships between age and friend report variables including companionship $(r=.36, p<.05)$, and conflict $(r=.34, p<.05)$. For the HFASD group, there were

Table 4 Group differences in friendship quality variables: observer based q-sort ratings of dyadic interactions

\begin{tabular}{|c|c|c|c|c|c|c|}
\hline & \multicolumn{2}{|c|}{ HF ASD group $(n=20)$} & \multicolumn{2}{|c|}{ Typically developing group $(n=22)$} & \multirow[t]{2}{*}{$Z$} & \multirow[t]{2}{*}{ Significance level } \\
\hline & Mean (SD) & Range & Mean (SD) & Range & & \\
\hline \multicolumn{7}{|l|}{ Q-sort scale } \\
\hline Positive orientation & $4.47(.63)$ & $3.05-5.86$ & $5.11(.60)$ & $3.72-6.25$ & 3.27 & .001 \\
\hline Cohesiveness & $4.43(.59)$ & $3.25-6.00$ & $4.81(.49)$ & $3.88-5.63$ & 2.29 & .020 \\
\hline Harmony & $4.49(.52)$ & $3.25-5.54$ & $5.11(.56)$ & $4.17-6.00$ & 3.24 & .001 \\
\hline Coordinated play & $2.97(.60)$ & $1.93-4.07$ & $3.87(.61)$ & $2.43-5.00$ & 3.84 & .001 \\
\hline Responsiveness & $4.78(.56)$ & $3.58-5.71$ & $5.43(.27)$ & $4.92-5.83$ & 3.73 & .001 \\
\hline Control & $2.62(.54)$ & $1.81-4.04$ & $2.11(.52)$ & $1.50-3.67$ & 3.29 & .001 \\
\hline
\end{tabular}

Mann-Whitney U Tests used

Table 5 Group differences in friendship quality variables: proband \& friend report on FQS

\begin{tabular}{|c|c|c|c|c|c|c|c|c|}
\hline & \multicolumn{2}{|c|}{$\begin{array}{l}\text { HFASD probands } \\
(n=20)\end{array}$} & \multicolumn{2}{|c|}{$\begin{array}{l}\text { HFASD friends } \\
(n=20)\end{array}$} & \multicolumn{2}{|c|}{$\begin{array}{l}\text { Typically developing } \\
\text { probands }(n=22)\end{array}$} & \multicolumn{2}{|c|}{$\begin{array}{l}\text { Typically developing } \\
\text { friends }(n=22)\end{array}$} \\
\hline & Mean (SD) & Range & Mean (SD) & Range & Mean (SD) & Range & Mean (SD) & Range \\
\hline \multicolumn{9}{|l|}{ FQS scale } \\
\hline Companionshp & $2.54(1.02)$ & $1.25-5.00$ & $2.16(.88)$ & $1.00-4.25$ & $2.22(.79)$ & $1.00-4.25$ & $1.93(.94)$ & $1.00-4.50$ \\
\hline Closeness & $3.64(.81)$ & $1.60-4.80$ & $3.96(.92)$ & $1.40-4.80$ & $4.21(.59)$ & $2.80-5.00$ & $4.28(.55)$ & $3.00-5.00$ \\
\hline Intimacy & $3.23(.86)$ & $1.60-4.60$ & $3.24(.62)$ & $1.80-4.20$ & $4.14(.55)$ & $2.60-5.00$ & $3.76(.41)$ & $3.00-4.80$ \\
\hline Help & $3.12(1.06)$ & $1.00-5.00$ & $3.51(1.20)$ & $1.60-5.00$ & $4.24(.68)$ & $2.80-5.00$ & $4.48(.55)$ & $3.20-5.00$ \\
\hline Conflict & $3.31(.67)$ & $1.75-4.25$ & $3.44(.71)$ & $2.00-4.75$ & $3.67(.49)$ & $2.75-4.50$ & $3.64(.45)$ & $3.00-4.50$ \\
\hline
\end{tabular}

Mann-Whitney U Tests used to test between group differences. Wilcoxon Signed Rank

Tests used to test significance of differences within dyads 
Table 6 Age and relationship development

\begin{tabular}{lll}
\hline & $\begin{array}{l}\text { HFASD group } \\
(n=20)\end{array}$ & $\begin{array}{l}\text { Typically developing } \\
\text { group }(n=22)\end{array}$ \\
\hline Q-sort scale & & \\
Positive orientation & $.53^{*}$ & NA $(1)$ \\
Cohesiveness & .04 & NA \\
Harmony & .30 & NA \\
Coordinated play & $.34^{*}$ & NA \\
Control & $-.49^{* *}$ & NA \\
Responsive & $.49^{* *}$ & NA \\
FQS scale & & \\
Conflict & -.02 & $.34^{*}$ \\
Companionship & .29 & $.36 *$ \\
Help & -.02 & .30 \\
Intimacy & -.12 & .24 \\
Closeness & -.06 & .23
\end{tabular}

Correlations are Spearman's rho (2-tailed)

(1) NAs used because Q-sort rating is for the dyad

* Correlation is significant at the $p<.05$ level (2-tailed)

** Correlation is significant at the $p<.01$ level (2-tailed)

significant relationships between the age of the proband and observer-report Q-sort based ratings for the positive orientation of the interaction $(r=.53, p<.01)$, coordinated play $(r=.34, p<.05)$, and responsiveness of the dyad ( $r=.49, p<.01)$, and a significant negative relationship for observed control $(r=-.49, p<.01)$.

To reduce the many friendship quality variables involving observer and participant based variables to a more parsimonious and meaningful set, we conducted a principal components factor analysis with varimax rotation. Factor analyses were conducted separately for HFASD and TYP, and then were combined when the factor structure proved similar across the groups. Factor loadings represent the degree to which each of the variables correlates with each of the factors. Factors with eigen values $>1.0$ were retained. Factor loadings of $>.6$ were interpreted. A three factor solution explained $70 \%$ of the variance. Factor 1 , which explained the largest proportion of the variance (40\%) consisted of all the Q-sort measures and we termed this factor "relationship appearance." The second factor, "internal tone of the friendship," which explained an additional $21 \%$ of the variance, consisted of most of the friend report measures of friendship quality except conflict, which loaded on its own factor. See Table 7.

\section{Relationship between Abstract Reasoning} and Friendship Quality

Multiple regression analyses were conducted to examine the relationship between demographic variables which had
Table 7 Factor loading for friendship quality measures

\begin{tabular}{lrrr}
\hline & \multicolumn{2}{l}{ Factor } \\
\cline { 2 - 4 } & 1 & 2 & \multicolumn{1}{l}{3} \\
\hline Q-sort scale & & & \\
Positive Orientation & $\mathbf{. 8 8}$ & .13 & .08 \\
Cohesiveness & $\mathbf{. 6 2}$ & -.02 & .16 \\
Harmony & $\mathbf{. 7 2}$ & .05 & -.43 \\
Coordinated Play & $\mathbf{. 8 4}$ & .07 & -.03 \\
Control &.$- \mathbf{7 5}$ & -.29 & .01 \\
Responsive & $\mathbf{8 3}$ & .18 & .02 \\
FQS scale & & & \\
Conflict & -.08 & -.23 & $\mathbf{. 8 4}$ \\
Companionship & .20 & $\mathbf{. 8 0}$ & -.28 \\
Harmony & .34 & $\mathbf{. 7 5}$ & -.41 \\
Intimacy & .20 & $\mathbf{. 7 3}$ & -.25 \\
Closeness & .14 & $\mathbf{. 8 1}$ & -.22 \\
\hline
\end{tabular}

demonstrated relationships with dependent variables in prior analyses, abstract reasoning, and aspects of relationship quality as captured by the factor scores. We completed separate analyses for Factor 1 "relationship appearance" and Factor 2 "internal tone of the friendship." Different sets of predictors emerged for Factors 1 and 2. Disability status (HFASD vs. TYP) and age both explained significant incremental variance in predicted relationship appearance (combined $r=.66, p=.001$ ). The ability to describe sorts on the DKEFs predicted internal tone of friendship $(r=.477, p=.002)$. Age, PPVT scores and ADI-R communication did not explain significant amounts of variance in either analysis. There were no significant relationships found between these variables and Factor 3 "relationship conflict."

\section{Discussion}

This first study of concept formation and concept identification in preadolescent and adolescent children with HFASD revealed a generalized impairment in concept formation, identification, and generation of sorting descriptions in this population. This deficit was not related to age or receptive vocabulary level, but rather to scores on the communication domain of the ADI-R, suggesting that it was pragmatic aspects of language, rather than receptive vocabulary, that were related to difficulties in abstract reasoning. Our findings of impairments in both concept identification and concept formation are at odds with the influential view that persons with ASD have specific difficulty with more complex forms of information processing 
(i.e. concept formation), rather than less complex forms of information processing (i.e. concept identification) (Minshew et al. 1997; Williams et al. 2006). Minshew, Meyer, and Goldstein (2002) concluded that there was a dissociation between these two components of abstract reasoning and that concept formation impairments could correctly discriminate $89 \%$ of subjects with autism in a group whose average age was 21 years. Given that the experimental tasks used in that study were similar to the ones used in this work, it remains possible that abstract reasoning abilities, and especially concept identification abilities, continue to improve through adolescence and early adulthood in individuals with HFASD. There have, in fact, been reports of the development of executive functions during this age period in HFASD (Happé et al. 2006). Thus our findings suggest that deficits in concept identification in children and teens with HFASD represent an area of developmental delay as opposed to deviance. Another developmental finding was Q-sort ratings of the interaction of both groups showed increasing positive orientation, coordination, and responsiveness. Future studies should investigate the extent to which individuals with HFASD "catch up" to those with typical development as this information is critical for treatment planning in adulthood.

Q-sort scores suggested that differences between the functioning of the HFASD and TYP dyads in a naturalistic play scenario could be detected by outside observers. Although their assessments of friendship intimacy were lower, child reports on the FQS suggested that children with HFASD and their friends did not differ from typical dyads in the amount of companionship they reported. This unexpected finding suggests that individuals with HFASD are experienced as valued partners in the important realm of companionship. It also bears mention that this critical information about the nuances of the relationships would have been lost if we had relied solely on outside observer reports. Concordance of perception of friendship quality between the children with HFASD and their friends also validated the reporting abilities of the children with HFASD and their ability to describe friendship qualities including companionship, security-intimacy and trust, help, and conflict.

Our findings add to the growing list of studies that demonstrate similarities in many aspects of friendships of HFASD and TYP preadolescents (Bauminger et al. 2008a, b). The current study again documented that companionship and shared perceptions of aspects of the friendship are present in these relationships. Given that companionship, in addition to intimacy, is considered an important aspect of adult relationships including marriage (Rhyne 1981) and mature friendship (Connidis and Davies 1992), this is a hopeful finding consistent with the premise that individuals with HFASD are capable of sustaining sophisticated adult interpersonal relationships. Future longitudinal research about these individuals' marital and friendship relationships throughout the lifespan may help illuminate strategies for achieving successful relationships, and for promoting mental health.

Results of the factor analysis also illustrated how two measures of friendship quality- observer- based measures of a laboratory-based interaction, and friends' self-reports of their relationships-captured different aspects of the friendship. The demographic variables age and disability status were related to observer-based assessments from the play scenarios, while abstract reasoning abilities explained about $20 \%$ of the variance in friends' perceptions of relationship quality. In future research it will be important to determine how other sources of individual differences including personality, co-morbid psychopathology, and characteristics of the family system, as well as biological factors, account for the remainder of the variance in friendship quality.

Gender composition of the dyad is another factor that may relate to differences in friendship characteristics. More HFASD dyads were cross-gendered. This may reflect the fact that individuals on the spectrum were not as aware of social norms, which in middle childhood and preadolescence dictate that friendships be single sex (Maccoby 1990). The friendships of boys and girls have been noted to differ in important ways including characteristic strategies used to resolve conflict. Girls are more prosocial in their goal and strategy orientation than boys (Rose and Asher 1999), although friendship quality and relationship number are related to strategies and goals in members of both genders (Rose and Asher 2004). Given the small number of girls in our sample, it was impossible to directly examine the influence of gender composition on the functioning of dyads. However, the study of gender differences in the mechanisms underlying friendship quality could potentially illuminate the range of interpersonal relationships open to individuals on the autism spectrum. Disability status of the dyads (whether they consisted of one or two children with a disability) is another important contributor to relationship quality, which was impossible to examine in great depth in this small sample. However, friendship quality analyses in this manuscript were completed independently for the groups with and without friends with disabilities and the pattern of findings did not change. We have, however, addressed this question in the bi-national sample (Bauminger et al. 2008a).

This study had several limitations. First, we only had complete data for Israeli participants, and the overall sample size is relatively small, thus limiting possible statistical analyses. Second, our sample consisted of high functioning persons with ASD, thus our results may not generalize to lower functioning and/or cognitively 
impaired individuals. Third, ADI-R, a parent-report measure based largely on reports of retrospective behavior was the principal means used to qualify participants into the study. It would have been preferable to have a current day clinician report measure as well. Fourth, to qualify for the study, a participant needed to have a friend of 6 months duration, and to be able to convince that individual to attend the session. This also may have biased our sample towards persons with ASD with relatively well-developed social relationship abilities. Fifth, this study leaves open the question of whether there are systematic biases in how individuals with HFASD select friends, and not just differences in the quality of ability to interact with friends, and that this is what is driving results.

Finally, and perhaps most importantly, the current study raises important issues related to treatment. First, companionate friendships, as opposed to the more intimate relationships generally associated with typical preadolescent and adolescent development, may be a more appropriate and attainable goal for HFASD preadolescents. The common and frequently successful recommendation to help children with autism to socialize through their special interests is consistent with this result.

This study also suggests that helping individuals develop abstract reasoning abilities is a potentially important, frequently unrecognized, and as yet untested treatment goal. It was striking that performance on concept formation and concept identification measures related so closely to friends' reports of relationship quality. In fact, existing social skills interventions for individuals with HFASD often implicitly scaffold concept formation abilities. For example, many of the social skills curricula for the HFASD population (i.e. Solomon et al. 2004) teach simple rules and/or templates for organizing social and non-social information (i.e. for identifying and explaining one's emotions across multiple contexts, for managing stressful situations, for engaging in reciprocal conversations about appropriate topics; and for identifying and generating solutions to daily problems). Parents also can be coached to verbally mediate the social world for their HFASD children during the course of semi-structured play, thereby helping the children to develop schemas for this form of dyadic interaction (Solomon et al. 2008). Finally, the "social stories" technique, which involves using narrative templates that can ultimately be elaborated and internalized by the individual to assist in managing situations encountered in daily life, has received empirical support (Quirmbach et al. 2009). All of these approaches implicitly enhance the ability of the individual with HFASD to script the social world, and to develop a larger and more flexible repertoire of behavior. In effect, the use and effectiveness of these techniques provides additional validation for our findings.
Acknowledgments This research was supported by the United States-Israel Binational Science Foundation (BSF), specifically a grant awarded to Drs. Nirit Bauminger and Sally Rogers. During the preparation of this manuscript, Dr. Solomon was supported by a K-08 Award from National Institutes of Mental Health (1-K-08 MH074967-01). Special thanks are extended to the children who took part in this study. The authors would like to express their appreciation to Anat Aviezer and Kelly Heung for coordinating the project in Israel and the USA, Lilach Gazit and John Brown for their help in data collection, and Ana Maria-Iosef, Ph.D. for statistical consulting.

Open Access This article is distributed under the terms of the Creative Commons Attribution Noncommercial License which permits any noncommercial use, distribution, and reproduction in any medium, provided the original author(s) and source are credited.

\section{References}

Ambery, F. Z., Russel, A. J., Perry, K., Morris, R., \& Murphy, D. G. M. (2006). Neuropsychological functioning in adults with Asperger syndrome. Autism, 10(6), 551-564.

American Psychiatric Association. (1994). Diagnostic and statistical manual of mental disorders (4th edition ed.). Washington, DC: Author.

Bauminger, N. (2004). The expression and understanding of jealousy in children with autism. Developmental Psychopathology., 16(1), 157-177.

Bauminger, N., \& Kasari, C. (2000). Loneliness and friendship in high-functioning children with autism. Child Development, 71, $447-456$.

Bauminger, N., \& Shulman, C. (2003). The development and maintenance of friendship in high-functioning children with autism: Maternal perception. Autism, the International Journal of Research and Practice, 7, 81-97.

Bauminger, N., Solomon, M., Aviezer, A., Heung, K., Gazit, L., Brown, J., et al. (2008a). Friendship in high-functioning children with autism spectrum disorder: mixed and non-mixed dyads. Journal of Autism and Developmental Disorders, 38(7), 12111229.

Bauminger, N., Solomon, M., Aviezer, A., Heung, K., Gazit, L., Brown, J., et al. (2008b). Children with autism and their friends: A multidimensional study of friendship in high-functioning autism spectrum disorder. Journal of Abnormal Child Psychology, 36(2), 135-150.

Berndt, T. J. (1989). Obtaining support from friends during childhood and adolescence. In B. Belle (Ed.), Children's social networks and social supports. New York: Wiley.

Berndt, T. J. (1996). Friendship quality affects adolescents' self esteem and social behavior. In W. M. Bukowski, A. F. Newcomb, \& W. W. Hartup (Eds.), The company they keep: Friendship during childhood and adolescence. New York: Cambridge University Press.

Bishop, D. V. M., \& Norbury, C. F. (2005). Executive functions in children with communication impairments, in relation to autistic symptomatology. Autism, 9(1), 29-43.

Boivin, M., Poulin, F., \& Vitaro, F. (1994). Depressed mood and peer rejection in childhood. Development and Psychopathology, 6, 483-498.

Buhrmester, D. (1990). Intimacy of friendships, interpersonal competence and adjustment during preadolescence and adolescence. Child Development, 61, 1101-1111.

Bukowski, W. M., Hoza, B., \& Boivin, M. (1994). Measuring friendship quality during pre- and early adolescence: The 
development and psychometric properties of the friendship qualities scale. Journal of Social and Personal Relationships, 11(3), 471-484.

Bukowski, W. M., Newcomb, A. F., \& Hartup, W. W. (1996). The company they keep: Friendship in childhood and adolescence. New York: Cambridge University Press.

Bukowski, W. M., \& Sippola, L. K. (1996). Friendship and morality: (How) are they related?. Cambridge: Cambridge University Press.

Connidis, I. A., \& Davies, L. (1992). Confidants and companions: Choices in later life. Journal of Gerontology, 47(3), 115-122.

Delis, D. C., Kaplan, E., \& Kramer, J. H. (2001). D-KEFS: Examiners manual. San Antonio: The Psychological Corporation.

Dunn, L. M., \& Dunn, L. M. (1997). Examiner's manual for the Peabody picture vocabulary test (3rd ed.). Circle Pines, MN: American Guidance Service.

Geurts, H. M., Corbett, B., \& Solomon, M. (2009). The paradox of cognitive flexibility in autism. Trends in Cognitive Sciences, 13(2), 74-82.

Grotevant, H., \& Cooper, C. (1986). Individuation in family relationships: a perspective on individual differences in the development of identity and role-taking skill in adolescence. Human Development, 29(2), 82-100.

Happé, F., Booth, R., Charlton, R., \& Hughes, C. (2006). Executive function deficits in autism spectrum disorders and attentiondeficit/hyperactivity disorder: Examining profiles across domains and ages. Brain and Cognition, 61(1), 25-39.

Hartup, W. W. (1995). The three faces of friendship. Journal of Social and Personal Relationships, 12(4), 569-574.

Hartup, W. W. (1996). The company they keep: Friendships and their developmental significance. Child Development, 67(1), 1-13.

Henault, I., \& Attwood, T. (2002). Sexual profile of individuals with Asperger's Syndrome: The need for understanding, support, and sex education. Paper presented at the Melbourne World Autism Congress.

Hill, E. F. (2004). Executive dysfunction in autism. Trends in Cognitive Science, 8, 26-32.

Hobson, R. P. (1996). Autism and the development of mind. Hillsdale, NJ: Erlbaum.

Hobson, R. P., \& Lee, A. (1999). Imitation and identification in autism. The Journal of Child Psychology and Psychiatry and Allied Disciplines, 40(4), 649-659.

Howard, B., Cohn, E., \& Orsmond, G. I. (2006). Understanding and negotiation friendships. Autism, 10(6), 619-627.

Jarrold, C., Boucher, J., \& Smith, P. (1996). Generativity deficits in pretend play in autism. British Journal of Developmental Psychology, 14(3), 275-300.

Jones, R. S. P., \& Meldal, T. O. (2001). Social relationships and Asperger's syndrome: A qualitative analysis of first-hand accounts. Journal of Learning Disabilities, 5(1), 35-41.

Lord, C., Rutter, M., \& LeCouteur, A. (1994). Autism diagnostic interview-revised: A revised version of a diagnostic interview for caregivers of individuals with possible pervasive developmental disorders. Journal of Autism and Developmental Disorders, 19, 185-212.

Luna, B., Garver, K. E., Urban, T. A., Lazar, N. A., \& Sweeney, J. A. (2004). Maturation of cognitive processes from late childhood to adulthood. Child Development, 75(5), 1357-1372.

Maccoby, E. E. (1990). The role of gender identity and gender constancy in sex-differentiated development. New Directions in Child Development, 4, 5-20.

Minshew, N. J., Goldstein, G., \& Siegel, D. J. (1997). Neuropsychologic functioning in autism: Profile of a complex information processing disorder. Journal of the International Neuropsychological Society, 3, 303-316.
Minshew, N. J., Meyer, J., \& Goldstein, G. (2002). Abstract reasoning in autism: Dissociation between concept formation and concept identification. Neuropsychology, 16(3), 327-334.

Orsmond, G. I., Krauss, M. W., \& Seltzer, M. M. (2004). Peer relationships and social and recreational activities among adolescents and adults with AUTISM. Journal of Autism and Developmental Disorders, 34(3), 245-256.

Ozonoff, S., Pennington, B. F., \& Solomon, M. (2006). Neuropsychological perspectives on developmental psychopathology. In D. Cicchetti \& D. J. Cohen (Eds.), Developmental psychopathology: Developmental neuroscience (Vol. 2, pp. 332-380). New Jersey: Wiley.

Park, K. A., \& Waters, E. (1989). Security of attachment and preschool friendships. Child Development, 60, 1076-1081.

Parker, J. G., \& Asher, S. R. (1993). The name assigned to the document by the author. This field may also contain sub-titles, series names, and report numbers. Friendship and friendship quality in middle childhood: Links with Peer group acceptance and feelings of loneliness and social dissatisfaction. Developmental Psychology, 29(4), 611-621.

Parker, J. G., Saxon, J., Asher, S. R., \& Kovacs, D. (1999). Dimensions of children's friendship adjustment: Implications for studying loneliness. In K. J. Rotenberg \& S. Hymel (Eds.), Loneliness in childhood and adolescence. New York: Cambridge University Press.

Paul, R. (2003). Promoting social communication in high functioning individuals with autistic spectrum disorders. Child and Adolescent Psychiatric Clinics, 12, 87-106.

Quirmbach, L. M., Lincoln, A. J., Feinberg-Gizzo, M. J., Ingersoll, B. R., \& Andrews, S. M. (2009). Social stories: mechanisms of effectiveness in increasing game play skills in children diagnosed with autism spectrum disorder using a pretest posttest repeated measures randomized control group designJournal of Autism \&. Developmental Disorders, 39(2), 299-321.

Rhyne, D. (1981). Bases of marital satisfaction among men and women. Journal of Marriage and the Family, 43(4), 941-955.

Rizzolatti, G., \& Fabbri-Destro, M. (2008). The mirror system and its role in social cognition. Current Opinion in Neurobiology, 18(2), $179-184$

Rogers, S. J. (2000). Interventions that facilitate socialization in children with Autism. Journal of Autism and Developmental Disorders, 30(5), 399-409.

Rogers, S. (2007). Nature of motor imitation problems in school-aged males with autism. Developmental Medicine and Child Neurology, 49(1).

Ropar, D., \& Peebles, D. (2007). Sorting preference in children with Autism: The dominance of concrete features. Journal of Autism and Developmental Disorders, 37(2), 270-280.

Rose, A. J., \& Asher, S. R. (1999). Children's goals and strategies in response to conflicts within a friendship. Developmental Psychology, 75(3), 749-763.

Rose, A. J., \& Asher, S. R. (2004). Children's strategies and goals in response to help-giving and help-seeking tasks within a friendship. Child Development, 75(3), 749-763.

Rubin, K. H., Bukowski, W. M., \& Parker, J. G. (1998). Peer interactions, relationships, and groups. In W. Damon \& N. Eisneberg (Eds.), Handbook of child psychology: Vol. 3. Social, emotional, and personality development (5th ed., Vol. 3, pp. 619-700). New York: Wiley.

Rutherford, M. D., \& Rogers, S. J. (2003). Cognitive underpinnings of pretend play in Autism. Journal of Autism and Developmental Disorders, 33(3), 289-302.

Rutherford, M. D., Young, G. S., Hepburn, S., \& Rogers, S. J. (2007). A longitudinal study of pretend play in Autism. Journal of Autism and Developmental Disorders, 37(6), 1024-1039. 
Sattler, J. M. (1988). Assessment of children (3rd ed.). San Diego: Author.

Saxe, R., \& Baron-Cohen, S. (2006). Theory of mind: A special issue of social neuroscience. London: Psychology Press.

Selman, R. L. (1990). Fostering intimacy and autonomy. In W. Damon (Ed.), Child development today and tomorrow. San Francisco: Jossey-Bass.

Shany, M., Lachman, D., Shalem, Z., Bahat, A., \& Zeiger, T. (2003). "Ma'akav:"Current mapping of reading and writing based on Israeli norms. Tel Aviv: Yesod (Hebrew).

Shulman, C., Yirmiya, N., \& Greenbaum, C. W. (1995). From categorization to classification: A comparison among individuals with autism, mental retardation, and normal development. Journal of Abnormal Psychology, 104, 601-609.

Siperstein, G. N., Leffert, J. S., \& Wenz-Gross, M. (1997). The quality of friendships between children with and without learning problems. American Journal of Mental Retardation, 102, 111-125.

Solomon, M., Goodlin-Jones, B. L., \& Anders, T. F. (2004). A social adjustment enhancement intervention for high functioning autism, Asperger's Syndrome, and Pervasive Developmental Disorder NOS. Journal of Autism and Developmental Disorders, 34(6), 649-668.

Solomon, M., Ono, M., Timmer, S., \& Goodlin-Jones, B. (2008). A pilot study of the effectiveness of Parent Child Interaction Therapy (PCIT) for children on the autism spectrum. Journal of Autism and Developmental Disorders.

Spear, L. P. (2000). The adolescent brain and age-related behavioral manifestations. Neuroscience and Biobehavioral Reviews, 24(4), $417-463$.
Stokes, M., \& Kaur, A. (2005). High-functioning autism and sexuality: A parental perspective. Autism, 9(3), 266-289.

Stokes, M., Newton, N., \& Kaur, A. (2007). Stalking, and social and romantic functioning among adolescents and adults with Autism spectrum disorder. Journal of Autism and Developmental Disorders, 37(10), 1969-1986.

Sullivan, H. S. (1953). The interpersonal theory of psychiatry. New York: Norton.

Tager-Flusberg, H. (1985). The conceptual basis for referential word meaning in children with autism. Child Development, 56, $1167-1178$.

Turner, M. (1999). Generating novel ideas, fluency performance in high-functioning and learning disabled individuals with Autism. Journal of Child Psychology and Psychiatry and Allied Disciplines, 40(1), 189-201.

Ungerer, J. A., \& Sigman, M. (1987). Categorization skills and receptive language development in autistic children. Journal of Autism and Developmental Disorders, 17(1), 3-16.

Verté, S., Geurts, H., Roeyers, H., Oosterlaan, J., \& Sergeant, J. (2006). Executive functioning in children with an Autism Spectrum Disorder: can we differentiate within the spectrum? Journal of Autism and Developmental Disorders, 36(3), 351372.

Williams, D., Goldstein, G., \& Minshew, N. (2006). The profile of memory function in children with Autism. Neuropsychology, 20(1), 21-29.

Yurgelun-Todd, D. A. (2007). Emotional and cognitive changes during adolescence. Current Opinion in Neurobiology, 17(2), 251-257. 